\title{
REVIEW \\ Masculinity lost: a systematic review of qualitative research on men with spinal cord injury
}

\author{
M Nolan
}

Study design: Systematic, thematic, narrative review of qualitative literature.

Objectives: To systematically review qualitative research that explores the impact of spinal cord injury (SCI) on the gendered experience of men with $\mathrm{SCl}$.

Methods: A systematic search of databases and hand search of relevant journals to provide a thematic narrative review of articles, providing sufficient depth of information, relevant participant quotes and phenomenological insight into the gendered experience of men with SCl. Identified studies are summarised and common themes extracted and discussed in relation to relevant literature on masculinity, disability and health.

Results: Eight papers, representing four separate studies met the review criteria for relevance and rigour. Three broad, overlapping themes describing the gendered experience of men with $\mathrm{SCl}$ were identified: 'lost masculinity', outlining the impact of SCl on traditional masculine identity, 'fighting back', describing the battle to regain and reclaim masculinity and integrate disability into a revised identity and 'beyond hegemony', referring to possibilities beyond adherence to traditional masculine scripts.

Conclusion: This review demonstrates a lack of explicit focus on men as gendered beings within the available qualitative literature. The findings are consistent with the limited quantitative data, which indicates that grappling with altered gendered identity is a central feature of life for men with SCl. Masculine identity emerges in this review as vulnerable to the impact of $\mathrm{SCl}$, and given the strong links identified between masculinity, rehabilitation and health, as an aspect of experience that warrants more attention than it has received.

Spinal Cord (2013) 51, 588-595; doi:10.1038/sc.2013.22; published online 23 April 2013

Keywords: spinal cord injury; gender; masculinity; qualitative systematic review

\section{INTRODUCTION}

The scarcity of literature on the female experience of spinal cord injury (SCI) evokes frequent comment. ${ }^{1-3}$ However, the lack of focus on the experience of men, other than as representative of general human experience, is overlooked and under-researched. ${ }^{4,5}$ Theories about gender and disability are scarce, ${ }^{6,7}$ and studies of gender often use gender as a synonym for women 'or open with a nod to gender and then glide on to women. ${ }^{8}$ Women typically provide the focus of discussion on gendered health inequalities, whereas men become a background feature, ${ }^{9-12}$ whose gender-specific needs receive insufficient attention. ${ }^{13-15}$

Men's health only became a specific area of policy concern in the UK in the early 90 's ${ }^{10}$ and even later in Ireland. ${ }^{16}$ It is increasingly recognised that research and health interventions should include a focus on gender. ${ }^{4-6,17,18}$ Although the International Classification of Functioning, Disability and Health ${ }^{19}$ situates gender as a key feature of the environmental and personal context within which functioning and disability occurs, the complexity of personal factors, including gender, evade easy categorisation. ${ }^{17,20,21}$

The predominance of white Caucasian men in SCI research is attributed to convenience sampling and epidemiological factors. ${ }^{22}$ The possible dominance of male concerns in the SCI and health literature results from a combination of factors, including the gender imbalance in sex distribution of SCI, (3.8/1 male to female), ${ }^{23}$ and a general tendency in health-care research to adopt a male norm ${ }^{18,24}$ or gender neutral focus. ${ }^{6}$

\section{FOCUS OF REVIEW}

The apparent lack of specific literature on the gendered experience of men with SCI prompted the current review, guided by the following question: What does qualitative research tell us about SCI and men as gendered beings? The objective was to systematically search for, and review, qualitative studies containing a focus on the gendered experience of men with SCI.

Qualitative literature, with its emphasis on the interpretation of individual experiences and subjective worldviews, has become increasingly established and acceptable within the field of health care ${ }^{25-27}$ and SCI. ${ }^{28-30}$ There is also a growing body of knowledge on systematic reviews of qualitative studies $27,31,32$ or 'qualitative evidence synthesis' to use the term favoured by the Cochrane Collaboration's Qualitative Research Methods Group. ${ }^{33}$ However, incorporating qualitative research in systematic reviews poses daunting methodological problems ${ }^{34}$ methods remain underdeveloped and under-evaluated ${ }^{35}$ and terminology is fluctuating and often conflicting. ${ }^{33,36}$

\section{METHODS}

A typology of reviews defines a qualitative systematic review as a method for integrating or comparing the findings from qualitative studies, characterised by 
an overarching narrative and the identification of themes across studies. ${ }^{33}$ It is distinguished from a meta-analysis by being interpretative rather than aggregative, its strength lies in its ability to broaden understanding of a particular phenomenon, and its weakness stems from its relative newness and debate about the precise strategies to be followed..$^{33}$ The current review consists of the following phases: identification of focus of review and published papers, summary and identification of key themes in each paper, selection of common themes across papers verified against relevant participant quotes, and interpretation in light of extant literature.

\section{IDENTIFYING PAPERS}

A comparison of methods for identifying qualitative research in electronic databases concluded that simple search strategies using broad-based terms are as effective as complex ones. ${ }^{37}$ CINAHL (Cumulative Index to Nursing and Allied Health Literature) is the most frequently cited database in qualitative health studies. ${ }^{32} \mathrm{~A}$ comprehensive search (Figure 1) was therefore carried out of CINAHL and four other electronic databases for the years 1991-2010: PsycINFO, PsychArticles, PubMed and Web of Knowledge using SCI in conjunction with the following terms: qualitative, gender, men, male and masculinity. The search was limited for pragmatic reasons to peer reviewed journals published in a 20 -year period. In addition, the following Journals were hand searched for the same period:

- Spinal Cord

- Disability and Rehabilitation

- Qualitative Health Research
- Rehabilitation Psychology

- International Journal of Rehabilitation Research

- Disability and Society

- Clinical Rehabilitation

- Sexuality and Disability

- Men and Masculinity

- Studies in Gender and Sexuality

This selection of journals is based on previous experience of useful sources, as well as evidence obtained from the search process about the potential location of relevant articles. Bibliographies of retrieved articles were also checked. Papers on men with SCI were included, which:

- were qualitative or contained a strong qualitative component

- were published in English in peer reviewed journals

- had a significant gender focus or a specific exploration of gender as part of the interpretation of findings

- provided participant quotes supportive of interpretations

Two papers, ${ }^{38,39}$ specifically exploring men's social and sexual experiences of dating behaviours and of disability identity following violently acquired SCI (VASCI), were excluded as they lacked an explicit gender focus. Almost no mention was made of men and masculinity beyond the inclusion of a male- only sample, and all findings could have applied equally well to women. Similarly, a study

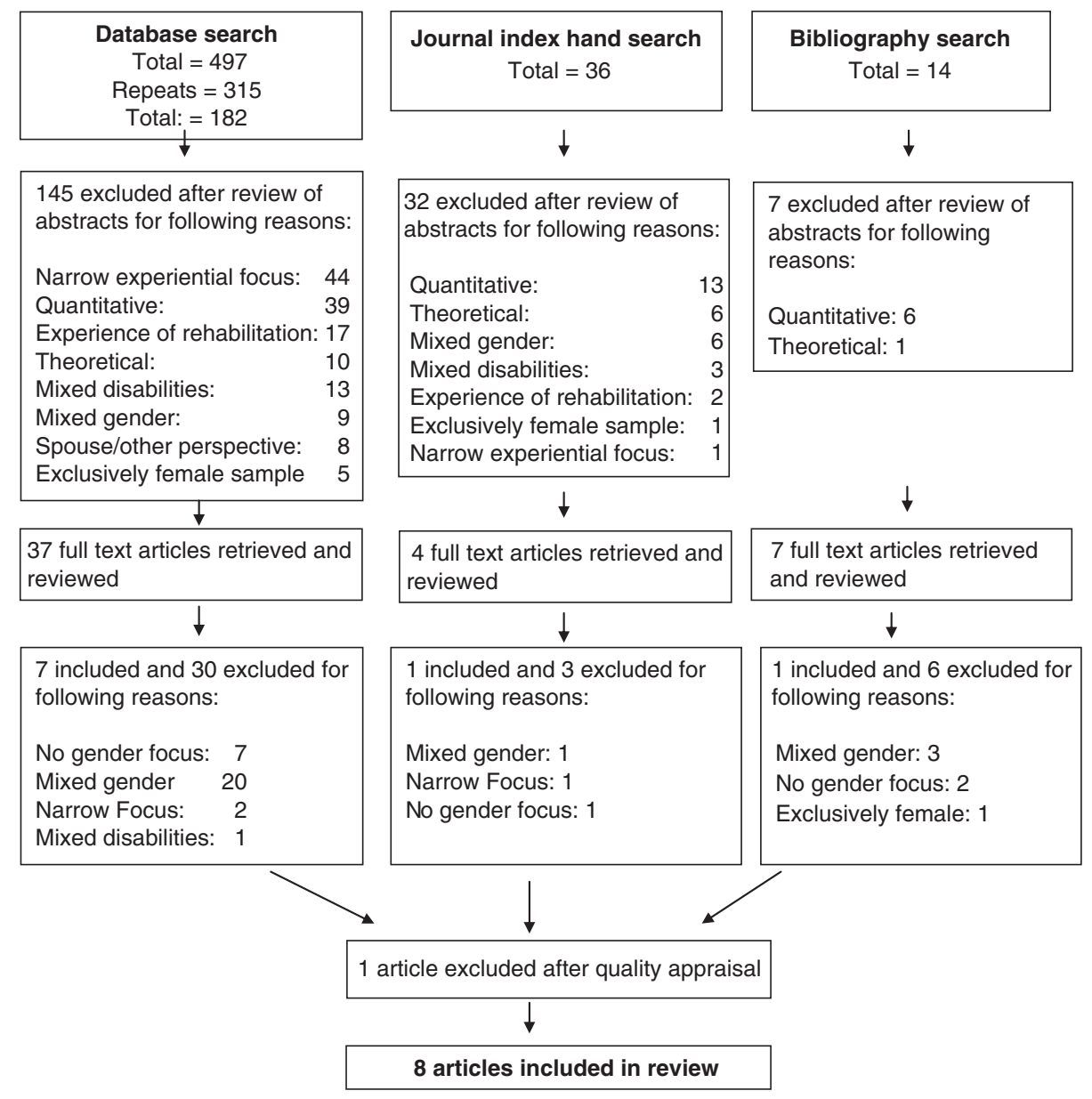

Figure 1 Literature search. 
of fathers with $\mathrm{SCI}^{40}$ was excluded as it lacked any emphasis on gender.

The procedure for evaluating qualitative research is not about judging strict adherence to rules or prescriptive criteria, but about weighing the appropriateness of various elements to the specific aims of the study. ${ }^{29}$ Maximising the conceptual yield of papers is more important than determining the robustness of research design, and critical appraisals as used in quantitative syntheses may be inappropriate. ${ }^{32}$ A review of qualitative systematic reviews concluded that the variety of approaches to appraisal reflects ongoing disagreement about the characteristics of good qualitative research, 'but also on whether criteria for quality in qualitative research should exist at all. ${ }^{32}$ Considerations of relevance to the review question and the illumination of subjective experience with supporting participant quotes therefore took precedence over a formal appraisal of quality or methodological rigour. However, a paper on sexuality ${ }^{41}$ was excluded on the basis that the authors presented an unexamined association between independence, masculinity and sexuality.

\section{OUTCOME OF REVIEW}

Eight papers, all seeking an insiders' perspective on the gendered experience of SCI, reporting on just four separate studies involving 32 participants (19-55 years), were reviewed. They were conducted in the UK, USA, Greece and Australia on men with paraplegia and tetraplegia (insufficient detail precluded determination of the exact proportion of each). Time since injury is not specified but spans at least a period of 6 months to 36 years. The review sought to identify themes and topics, which emerge when researchers explore, directly or indirectly, gendered masculinity. Relevant aspects of each paper are presented in Table 1.

\section{RESULTS}

Semi-structured interviews were the usual method of data collection, although the single-case study also included participant observation. ${ }^{42}$ Data analysis included narrative analysis, ${ }^{42-45}$ grounded theory ${ }^{46,47}$ and thematic analysis. ${ }^{48,49}$ Studies were carried out under the auspices of sports psychology, social work, anthropology and occupational therapy. A brief summary of each is followed by an integrative, thematic review of the impact of SCI on masculinity.

In a comprehensive study of 14 injured rugby players, gender provides a significant focus in three articles dealing with narrative identity dilemmas, ${ }^{43}$ the use of common metaphors ${ }^{45}$ and the construction of coherence following injury. ${ }^{45}$ The embodied, masculine identities of these men, largely formed through athletic prowess, were fundamentally threatened by the experience of acquired disability. The desire to reclaim a restored self became a self-defeating quest for the majority, as reliance on dominant conceptions of masculinity acted to constrain the construction of new body-self relationships. The 'restitution narrative', characterising 11 of the 14 post injury stories, typified by metaphors of war, sporting battles, fights and comebacks expressed a strong, active desire to return to former valued lives. Such narratives are framed and constrained by social structures and available cultural narratives.

Sexual identity following SCI is explored in six Greek men, living in a culture, in which the authors argue, sexuality in relation to disability is a taboo subject and masculinity is strongly associated with physical action and the pursuit of sexual encounters. ${ }^{48,49}$ Prevailing societal attitudes about dominant masculinities and asexuality of those with impairments is considered to operate as external barriers to sexual expression for the disabled, while the focus on performative excellence threatens masculine identity. The loss of social power, independence and traditional male traits is described as 'a metaphorical castration. ${ }^{49}$ Dominant societal values regarding masculinity, sexuality and disability created internalised oppression, and a submerging of male status by impairment and asexualisation.

In a study of men with VASCI, the experience of disability resulted in strong feelings of emasculation. ${ }^{46,47}$ SCI effected a schism in the lives of already impoverished men, further marginalised by disability and dependency. Participants spoke of the challenge to masculinity, and SCI manifested itself most explicitly in how participants perceived themselves as men. Constant comparisons between current and past lives were common, and participants experienced a lack of independence, inability to engage in traditional sexual relations, changes in body image and feelings of vulnerability. Male identity, and the contextual social understanding of man, defined by independence, sexual virility and the capacity and duty to defend self and loved ones, were violated by disability. Masculinity became a contested identity category and, unlike race or ethnicity, was continuously challenged by self and others.

A single-case study provided insight into a particular interweaving of masculinity, sexuality and immigration. ${ }^{42}$ As in the description of restitution narratives, ${ }^{44}$ the dominant metaphor was one of the battle in the face of invalidated adulthood and masculine identity. Robert labels himself as 'a child of war', ${ }^{42}$ and his relentless struggle to reconcile his infantilised and feminised body with a culturally scripted masculinity is described. As a former athlete and activist who valued success in traditionally masculine cultural domains, Robert was determined to recover lost status, adulthood, identity and invalidated masculinity. The case study illustrates the importance of paying attention to the embodied individual within the injured body.

\section{THEMATIC SYNTHESIS}

Three dominant, themes emerged from this review; 'lost masculinity', 'fighting back' and 'beyond hegemony'.

\section{'Lost masculinity'}

Taken together, these eight papers tell stories of lost, diminished and vulnerable masculinity resulting from SCI. Participants were all men considered to be living their lives according to 'macho', hypermasculine scripts based on elements of physical prowess, athletic display, gang membership and bodily performance, socialised in cultural contexts emphasising dominant forms of masculinity. What emerges from these articles is a strong sense that traditional forms of masculinity are challenged by SCI, which impacts dramatically on men's self-presentation, body image, sexuality and relationships. Identity dilemmas, evoked by a sense of lost masculinity and damaged sexual identities, emerge as the central and salient topic around, which other changes are situated.

The authors describe how masculine identity for participants is questioned by $\mathrm{SCI},{ }^{45}$ made precarious, ${ }^{48}$ invalidated, ${ }^{42}$ complicated, challenged and diminished, ${ }^{46,47}$ thus highlighting the insidious power and limitations of contemporary masculinity ${ }^{43}$ and the poverty of culturally endorsed masculine scripts. ${ }^{42}$ The sense of loss is powerful and, possibly for most participants, resulted in a preoccupation with previous levels of functioning and a yearning for what was or what might have been.

Each paper contains strong statements detailing participant's attempts to grapple with personal definitions of masculinity. Language used by participants is dramatic, poignant and evocative of loss, transformation and radical restructuring of bodies, selves, 


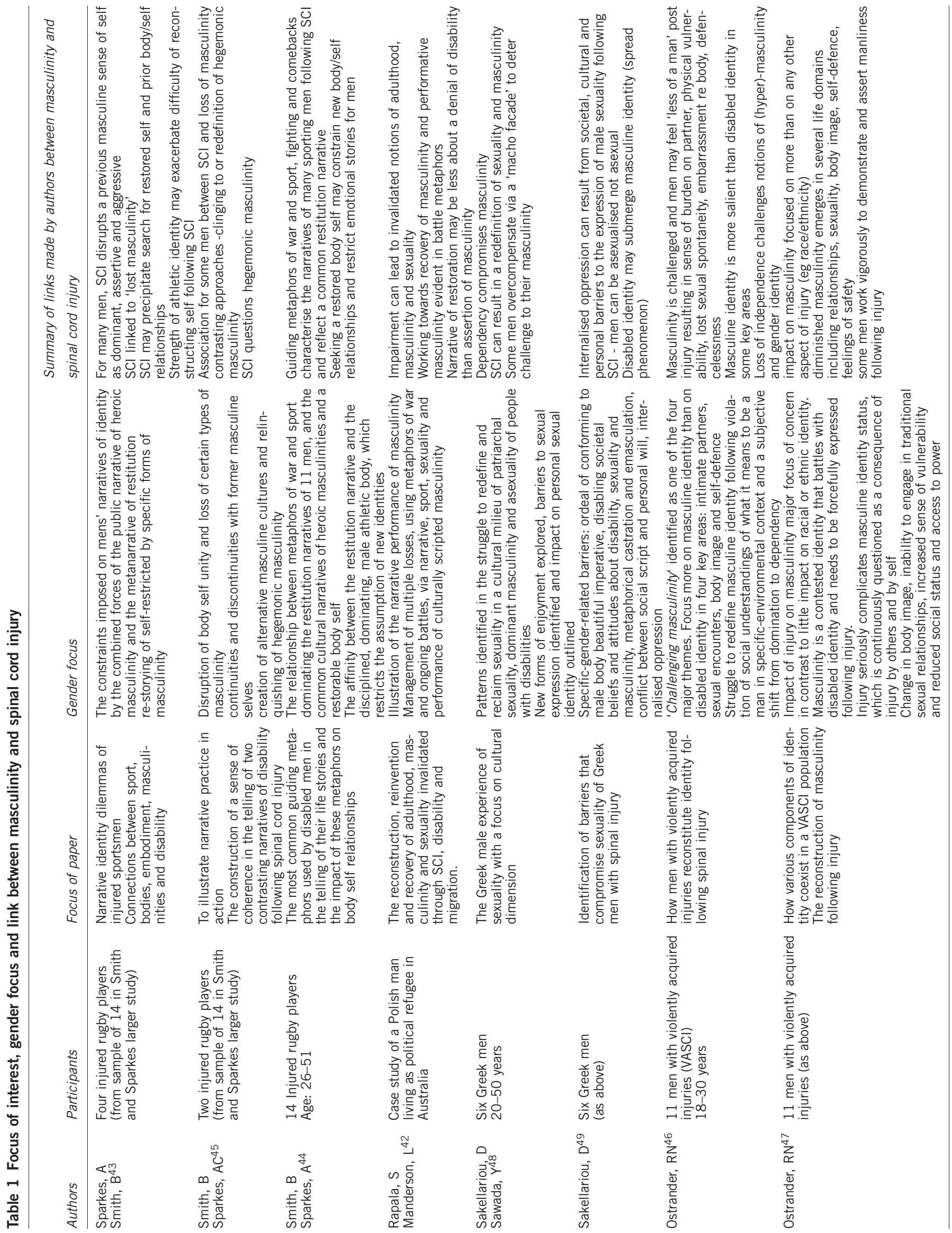


Table 2 Participant quotes supporting each theme

\begin{tabular}{|c|c|c|}
\hline Theme 1: lost masculinity & Theme 2: fighting back & Theme 3: beyond hegemony \\
\hline $\begin{array}{l}\text { 'when you are able-bodied you don't really think about } \\
\text { being a man, not properly' } 43 \\
\text { 'I'm useless as a disabled man...my manhood has been } \\
\text { shattered'43 } \\
\text { 'I'm half of man...I'm always gonna need help'47 } \\
\text { 'Your masculinity goes. It's ripped right out of you'45 } \\
\text { feeling like a man almost evaporates'43 } \\
\text { 'in a way you have lost your masculinity....one of the } \\
\text { biggest shocks that you have to face when you become } \\
\text { disabled' } 43 \\
\text { 'they remember me healthy, strong. And now a wreck of } \\
\text { that man'42 } \\
\text { 'that kinda take a little piece of your manhood'47 } \\
\text { 'I started thinking about my sexuality from the first } \\
\text { moments after my accident. I felt like being castrated, } \\
\text { emasculated.. } 48 \\
\text { 'an issue that bothers me, when I have to ask a girl to } \\
\text { help me with taking off my pants, because manhood is } \\
\text { directly associated with having sex, doing.' } 49 \\
\text { 'the body beautiful image makes me feel bitter and } \\
\text { resentful' } 49\end{array}$ & $\begin{array}{l}\text { 'I'm certainly not going to give in and be weak or } \\
\text { touchy feely and all feminised by the whole } \\
\text { thing...I've got balls and I'll fight this' } 44 \\
\text { 'will do everything to return, I will give } \\
\text { everything, you know, to make a step on my own } \\
\text { legs'. } 42 \\
\text { 'To this day I fought, I fight, and I will continue } \\
\text { to fight'42 } \\
\text { 'I'm gonna fight as Iong as I can fight'47 } \\
\text { 'I do think that I'll make a comeback and walk } \\
\text { again at some point in time. I won't stop fighting } \\
\text { until I can do that....I could never give up or stop } \\
\text { fighting 'cos that again would be like saying I am } \\
\text { a failure and really a bit of a wimp, not a proper } \\
\text { man'44 } \\
\text { 'I look at it all as something that will be fixed'45 } \\
\text { 'It's like sport, disability is an enemy that I must } \\
\text { beat'44 } \\
\text { 'one long battle against the body until medicine } \\
\text { finds a cure and I can walk again'44 }\end{array}$ & $\begin{array}{l}\text { 'I am the same, I am still John... the only thing } \\
\text { is, my wings are now trimmed' } 49 \\
\text { 'I want to challenge other people and draw } \\
\text { attention on me and I really do make a point of } \\
\text { getting everybody talking with me' } 49 \\
\text { 'I've come to think of my body as part of me and } \\
\text { I accept that it doesn't do things that it could in } \\
\text { the past' } 44 \\
\text { 'I've been reborn, and have become a better } \\
\text { person since becoming disabled' } 44 \\
\text { 'I had to get out of that masculine thing if I } \\
\text { wanted to move on....I'm secure enough now to } \\
\text { reject this masculine crap' } 45 \\
\text { 'I've a new lease of life. I feel as if I have been } \\
\text { reborn, starting all over again' } 45 \\
\text { 'Its an opportunity to explore yourself and } \\
\text { become a better person' } 44 \\
\text { 'I was hiding behind masculinity beforehand' } 45 \\
\text { 'The satisfaction I get now is of a different kind } \\
\text { and it can sometimes be more intense than the } \\
\text { one I had before' } 48\end{array}$ \\
\hline
\end{tabular}

relationships and lifeworlds. Relevant quotes supporting each theme are presented in Table 2.

For most participants, SCI led, temporarily or permanently, to feelings of vulnerability, erosion of status and emasculation. Concerns about body image, sexual prowess, impact on partners and sexual relationships expressed in statements like 'I really don't want no relationship because of the chair and the luggage I bring, ${ }^{47}$ and 'would you like to go to bed with me... and my personal assistant', ${ }^{48}$ were also reflective of lost masculinity.

\section{'Fighting back'}

The male use of military metaphors to capture the illness struggle is noted in two papers in this review. ${ }^{42,44}$ The sense of loss and the challenge to identity proves overwhelming for some men, and the pull of past bodyselves precipitates a submersion in regret and a frantic search for recovery, restitution and a returned hegemonic masculinity. This common response is expressed in the language of war and sport, battle ${ }^{42,44}$ and culturally scripted masculine prowess.

The double-edged role of a strong athletic identity is apparent in these studies. For the rugby players, SCI represented an end to a sporting career, whereas for Robert, a return to the 'testosteronecharged world of competitive sport', ${ }^{42}$ represented a reclamation of masculine identity. The fight to regain and reclaim masculinity largely emerges as a troubled endeavour, and, while many participants 'worked vigorously to show that they remained men', ${ }^{47}$ it was often at the expense of integrating disability into a revised identity.

\section{'Beyond hegemony'}

This theme captures a sense of how men may negotiate the incompatibility between disability and masculine ideals. For participants in this review, possibilities beyond adherence to traditional masculine scripts were only glimpsed, but nevertheless emerged as viable for some. The focus on continuity in the midst of change, the appraisal of SCI as a challenge and grappling with the opportunity for change and transformation, provoked by a questioning of previous identities, represent other possibilities. The quest narrative, ${ }^{44}$ captures key elements of this process, including the need to 'move past the obsession with the body' ${ }^{45}$ elicit meaning from the disability experience and reconstruct a differently valued self.

A rejection and redefinition of hegemonic masculine sexuality was identified for men able to appraise SCI as an opportunity to develop and become less self-focused. ${ }^{48}$ Sexual performance for some was expanded and redefined through experimentation, improvisation and remapping of erogenous zones. The perceived burden on partners could be offset by improved intimacy and enhanced sexual responsiveness to their needs, leading to feelings for some participants of 'being more like a man' again. ${ }^{47}$

The possibility of other versions of masculinity emerging was less likely in the VASCI group living in a social context, requiring the continuous expression of masculinity, thus increasing the challenge of living with disability, and militating against the integration of injury into new identities. ${ }^{46,47}$ Not surprisingly, a focus on defencelessness was specific to those with VASCI, but can perhaps be seen as an extreme and environmentally appropriate, expression of the vulnerability expressed by many, if not most, participants in this review.

\section{DISCUSSION}

This review provides evidence of a striking lack of focus on men as gendered beings within the available qualitative SCI literature. It also identifies a thematic consistency in that literature that supports classic papers $^{50,51}$ on masculinity and SCI. The findings are consistent with the limited quantitative data that indicates that grappling with altered gendered identity is a feature of life after SCI, which warrants explicit consideration. ${ }^{5,14,22,52,53}$ It adds depth to an already existing body of knowledge, elucidating the impact of SCI on identity, ${ }^{43,54,55}$ and has implications for health-care professionals seeking to understand individual responses to SCI and to self-management of health during and following rehabilitation. 
Although a range of potential effects of SCI on masculinity are identified in this review, it is constrained by a focus on a limited range of hypermasculinities, making it difficult to infer the meanings of lost masculinity for wider groups of men. The masculinity lost in these articles is of the hegemonic variety associated with dominance, assertiveness and aggressiveness. Participants were men who lived their lives according to 'macho', hypermasculine scripts, for whom the atrophy of the body posed a particular threat to identity. The impact of SCI on masculinity in this review is captured in three major themes; 'lost masculinity', outlining the powerful impact of SCI on identity and 'fighting back', describing a characteristic masculine response style and 'beyond hegemony', indicating possibilities beyond adherence to traditional conceptions of masculinity.

Gerschick and Miller ${ }^{50}$ describe three dominant, interwoven frameworks that guide disabled men's relationships to hegemonic standards: reliance, involving continued attempts to meet traditional expectations; rejection, involving the creation of alternative masculine identities and reformulation, involving a redefinition of masculinity. This work has been criticised for being removed from the lived experience of interpersonal relationships. ${ }^{56}$ However, themes identified in this review are consistent with Gerschick and Miller's formulation and provide support for some generalisation of current findings. 'Fighting back' is consistent with a reliance on dominant standards and 'Beyond hegemony' reflects rejection and recognition of limitations inherent in those standards. Reformulation, involving a redefinition of manhood along new lines is apparent in the use of rebirth metaphors and the appraisal of SCI as a vehicle for increased self- awareness.

Masculine identity is inescapably connected to sexual prowess. ${ }^{42,46,48,57,58}$ The redefinition of disabled masculine sexuality as less about sexual objectification and more about sexual intimacy, identified in this review has been previously described. ${ }^{56}$ Review findings are consistent with conceptions of conflict between traditional masculinity and disability, and of acquired disability as a particular crisis for men whose identity construction is based on physicality, invulnerability and the ability to carry out conventional gender roles. ${ }^{52,58-60}$ While there may be several masculinities, it is likely that, among the many comparisons of self that men make as a result of injury, the one with hegemonic masculinity plays its part. The collision between masculinity and disability may then create an erosion of masculine status. ${ }^{7}$

Despite compelling evidence that disability strongly impacts gendered experience, ${ }^{7,61,62}$ that illness and disability affect men and women differently, ${ }^{63}$ that gender has a key role in patterns of health and illness ${ }^{10,64}$ and is related to health beliefs and behaviours, ${ }^{65-67}$ the gendered experience of men with SCI is strikingly absent from academic papers. This despite, or even perhaps because, of the dominant male focus within the SCI literature. The lack of information is surprising, given the focus of qualitative literature on lived experience, the obvious impact of SCI on bodily functioning and body image and the theorised and experiential links between the body and masculinity. ${ }^{43,59,68-70}$ The body and bodily performance, made vulnerable by injury, is a basic constituent of being a man and the need to pay scrupulous attention to 'a leaky, unreliable and often troublesome' body, ${ }^{57}$ 'feminised and infantilised' by injury, ${ }^{42}$ and experienced as a battleground, ${ }^{44}$ is a daunting task.

The absence of gender focus may be attributed to the assumption of asexuality or infantilism linked to disability, ${ }^{21,58,71,72}$ the gender neutrality of health care, ${ }^{6,72,73}$ unexamined assumptions of the nondisabled community, ${ }^{74,75}$ the predominance of gender similarities over differences, ${ }^{76,77}$ the salience of disability over gender ${ }^{78}$ or the tendency to see disability as the dominant identity marker. ${ }^{21,79-81}$
SCI has multiple ramifications for personal, social, professional and domestic responsibilities and, while gender is not the only, and not even necessarily the most important, social identity, it is 'the most pervasive, visible and codified. ${ }^{82}$ We cannot 'not do gender' as it is a fundamental part of identity formed in interaction with others. ${ }^{83}$ As a concept, gender seems to go in and out of fashion and benefit from periodic revisitation. ${ }^{84}$ Conceptualisations of both gender and masculinity are problematic, ${ }^{11,68,85}$ although clarification of the complexities involved is beyond the scope of this paper. It is clear that a nuanced understanding of the meaning of gender beyond sex roles or gender inequities, and of masculinities beyond a single hegemonic variety is required. ${ }^{11,68}$ It is also necessary to take the implications of intersectionality, or gender as only one of many categories of identity, into account. ${ }^{82,86,87}$

The multiplicity of links between gender and health is increasingly being recognised and health behaviours seen as ways of doing gender. $^{10,65,88-90}$ Given the prevalence of secondary complications ${ }^{91}$ and higher rates of contact with health-care services following SCI, ${ }^{92}$ all influences on health behaviours, including gender, warrant consideration. Ways of doing rehabilitation, like ways of doing health, are ways of doing gender. $^{70}$ Although there is much discussion of the potentially negative impact of masculine socialisation, some aspects of traditional masculinities have been linked to good outcomes. ${ }^{14,52,53}$ Rehabilitation may be a crucial time for men as illness can provoke an altered relationship with the self. ${ }^{69,70}$ Although men may have less self/body awareness than women in times of health, many are keen to maintain and become experts in times of ill-health. ${ }^{70}$ Essential bodily monitoring and maintenance may therefore function to signify masculinity rather than loss of masculinity.

Rehabilitation professionals have a key role to play in providing gender-aware care and interventions. ${ }^{60}$ However, the detached clinical gaze may ignore or minimise the impact of SCI on the embodied, gendered self. ${ }^{93}$ In a review of the rehabilitation experience, the calibre and vision of the staff and the capacity to convey a sense of being valued as a human being has been identified as the most important dimension of the rehabilitation experience. ${ }^{30}$ Being a human being necessarily entails being a gendered human being. It is crucial that professionals value long established gender identities for those grappling with newly damaged bodies. Gender, already rendered vulnerable, cannot be erased by the visibility of disability, and instead must be affirmed to bolster a sense of continuity at a time of considerable change. Although identity dilemmas may constitute the central issue for those rebuilding lives after injury, ${ }^{43,54,55,93}$ alterations in self-identity and a focus on body esteem do not fit easily with demands for achievable, time constrained goals and the pursuit of measurable rehabilitation outcomes. As men's adjustment to SCI is increasingly understood to be mediated by conceptions of masculinity, ${ }^{14,52,53}$ it is important to seek a deeper understanding of how multiple masculinities are lived out and how versions other than constraining, conventional ones may be promoted and fostered.

The notion of gender as something to be reconsidered and reconfigured following injury may be helpful in understanding some of the puzzling behaviours evident during, and following, rehabilitation for example, self-neglect as an indicator of failed hegemonic masculinity or macho bravado as a factor in apparently unconcerned or challenging behaviour. A compulsion to overcompensate, cover and minimise impairments and a refusal to reveal emotion may be a response to feelings of emasculation. Efforts to retain a masculine self may be implicated in apparent non-compliance during rehabilitation programmes or in neglect of critical self-care following discharge. 
Bodily anxieties may be masked to preserve masculine identities ruptured by SCI and professionals need to be alert to the tendency for some men to create a defensive space within which to nurse wounded masculinity, or mask a terror of disablement. Men may become marginalised within the gender order as a result of injury, and may require additional supports to define masculinity in non-traditional terms.

A variety of rehabilitation interventions ranging from peer support and mentoring programmes to the exploration of individual narratives of masculinity, injury and health may offer men alternative images of masculinity. Group work and self-management programmes can provide an opportunity to reinforce the positive characteristics associated with traditional masculinity, as well as deliver strong peer and professional messages about less traditional masculine scripts. A strong preference for stories of heroic masculinity can, however, limit the telling of other stories and restrict the emergence of alternative versions of masculinity, ${ }^{45}$ while an overemphasis on physicality may lead to the neglect of other forms of self-expression or identity development. ${ }^{51,57}$ Recently identified, innovative health promotion possibilities for men with SCI, ${ }^{94}$ offer additional possibilities for the expansion of resilient masculinities.

\section{LIMITATIONS}

This review is limited by being arbitrarily restricted to papers published before 2011 and in peer reviewed journals, although many significant works appear in book, chapter or dissertation format. This absence of grey literature means the exclusion of a rich body of work on the personal autobiographical experience of SCI, as well as that contained in unpublished work. Additional work, including a recent qualitative study of health narratives, which contributes to a richer understanding of masculinity and $\mathrm{SCI}^{94}$ is excluded from this review. Finally, without a companion study of women, the themes identified in this study cannot be exclusively attributed to men.

\section{CONCLUSION}

This review of 20 years of qualitative literature suggests a surprising lack of focus on men as gendered beings. Masculine identity emerges in this review as vulnerable to the impact of acquired disability and, given the strong links between masculinity, rehabilitation and health, as an aspect of SCI that warrants more attention than it has received.

\section{DATA ARCHIVING}

There were no data to deposit.

\section{CONFLICT OF INTEREST}

The authors declare no conflict of interest.

\section{ACKNOWLEDGEMENTS}

I would like to thank Anne-Marie Casey for assistance with searching and Michele Verdonck for assistance with referencing.

1 Quigley MC. Impact of spinal cord injury on the life roles of women. Am J Occup Ther 1995; 49, 780-786.

2 Isaksson G, Skar L, Lexell J. Women's perception of changes in the social network after a spinal cord injury. Disabil Rehabil 2005; 27, 1013-1021.

3 Chau L, Hegedus L, Praamsma M, Smith K, Tsukada M, Yoshida K et al. Women living with a spinal cord injury: perceptions about their changed bodies. Qual Health Res 2008; 18, 209-221.

4 Robertson S. Men and Disability. In: Swain J, French S, Barnes C and Thomas C (eds) Disabling Barriers, Enabling Environments, 2nd edn. Sage Publications: London, 2004, pp 75-80.
5 Sheldon AP, Renwick R, Yoshida KK. Exploring body image and self-concept of men with acquired spinal cord injuries. Am J Mens Health 2011; 5, 306-317.

6 Thorne S, McCormick J, Carty E. Deconstructing the gender neutrality of chronic illness and disability. Health Care Women Int 1997; 18, 1-16.

7 Gerschick TJ. Toward a theory of disability and gender. Signs 2000; 25, 1263-1268.

8 Turshen M. Gender and Health. J Public Health Policy 2007; 28, 319-321.

9 Sabo DF, Gordon DFE. Men's health and illness. Gender, Power, and the Body. Sage Publications: Thousand Oaks, US, 1995.

10 Cameron E, Bernardes J. Gender and disadvantage in health: men's health for a change. Sociol Health IIIn 1998; 20, 673-693.

11 Connell RW, Messerschmidt JW. Hegemonic masculinity. Gend Soc 2005; 19 , 829-859.

12 Connell RW. Change among the gatekeepers: men, masculinities, and gender equality in the global arena. Signs 2005; 30, 1801-1825.

13 Shakespeare T, Gillespie-Sells K, Davies D. The sexual politics of disability: Untold desires. Burns \& Oates: London, 1996.

14 Schopp LH, Good GE, Mazurek MO, Barker KB, Stucky RC. Masculine role variables and outcomes among men with spinal cord injury. Disabil Rehabil 2007; 29, 625633

15 Varanka JJ. Mainstreaming men into gender sensitive health policies. J Mens health 2008; 5, 189-191

16 Richardson N, Carroll PC. Getting men's health onto a policy agenda-charting the development of a National Men's Health Policy in Ireland. J Mens health 2009; 6, $105-113$.

17 Scherer MJ, Dicowden MA. Organizing future research and intervention efforts on the impact and effects of gender differences on disability and rehabilitation: the usefulness of the International Classification of Functioning, Disability and Health (ICF). Disabil Rehabil 2008; 30, 161-165.

18 Niemeier JP. Unique aspects of women's emotional responses to disability. Disabil Rehabil 2008; 30, 166-173.

19 World Health Organization. International Classification of Functioning, Disability and Health: ICF. World Health Organization: Geneva, Switzerland, 2001.

20 Imrie R. Demystifying disability: a review of the International Classification of Functioning, Disability and Health. Sociol Health IIIn 2004; 26, 287-305.

21 Lutz BJ, Bowers BJ. Disability in everyday life. Qual Health Res 2005; 15, 1037-1054.

22 Krause JS, Broderick LE, Broyles J. Subjective well-being among African-Americans with spinal cord injury: an exploratory study between men and women. NeuroRehabilitation 2004; 19, 81-90.

23 Wyndaele M, Wyndaele JJ. Incidence, prevalence and epidemiology of spina cord injury: what learns a worldwide literature survey? Spinal Cord 2006; 44 523-529.

24 Emslie C, Hunt K. Men, masculinities and heart disease. Curr Sociol 2009; 57, 155-191.

25 Popay J, Rogers A, Williams G. Rationale and standards for the systematic review of qualitative literature in health services research. Qual Health Res 1998; 8, 341-351.

26 Yardley L. Dilemmas in qualitative health research. Psychol Health 2000; 15, 215-228.

27 Sandelowski M. Using qualitative research. Qual Health Res 2004; 14, 1366-1386.

28 Duggan $\mathrm{CH}$, Dijkers M. Quality of life after spinal cord injury: a qualitative study. Rehabil Psychol 2001; 46, 3-27.

29 Hammell KW. Quality of life after spinal cord injury: a meta-synthesis of qualitative findings. Spinal Cord 2007; 45, 124-139.

30 Hammell KW. Experience of rehabilitation following spinal cord injury: a metasynthesis of qualitative findings. Spinal Cord 2007; 45, 260-274.

31 Finfgeld DL. Metasynthesis: the state of the art-so far. Qual Health Res 2003; 13, $893-904$.

32 Dixon-Woods M, Booth A, Sutton AJ. Synthesizing qualitative research: a review of published reports. Qual Res 2007; 7, 375-422.

33 Grant MJ, Booth A. A typology of reviews: an analysis of 14 review review types and associated methodologies. Health Info Libr J 2009; 26, 91-108.

34 Dixon-Woods M, Fitzpatrick $\mathrm{R}$, Roberts $\mathrm{K}$. Including qualitative research in systematic reviews: opportunities and problems. J Eval Clin Pract 2001; 7, 125-133.

35 Dixon-Woods M, Agarwal S, Jones D, Young B, Sutton A. Synthesising qualitative and quantitative evidence: a review of possible methods. J Health Serv Res Policy 2005; 10, 45-53B.

36 Hughes N, Closs SJ, Clark D. Experiencing cancer in old age: a qualitative systematic review. Qual Health Res 2009; 19, 1139-1153.

37 Flemming K, Briggs M. Electronic searching to locate qualitative research: evaluation of three strategies. J Adv Nurs 2007; 57, 95-100.

38 Bastanfar RB, Crewe N. A qualitative study of the dating behaviours of men with spinal cord injury. SCl Psychosoc Proc 2005; 18, 76-82.

39 Hernandez B. A voice in the chorus: perspectives of young men of color on their disabilities, identities, and peer-mentors. Disabil Soc 2005; 20, 117-133.

40 Duvdevany I, Buchbinder E, Yaacov I. Accepting disability: the parenting experience of fathers with spinal cord injury (SCI). Qual Health Res 2008; 18, 1021-1033.

41 Basson P, Walter S, Stuart A. A phenomenological study into the experience of their sexuality by males with spinal cord injury. Health SA Gesondheid 2003; 8, 3-11.

42 Rapala S, Manderson L. Recovering in-validated adulthood, masculinity and sexuality. Sex Disabil 2005; 23, 161-180.

43 Sparkes AC, Smith B. Sport, spinal cord injury, embodied masculinities, and the dilemmas of narrative identity. Men Masc 2002; 4, 258-285. 
44 Smith B, Sparkes A. Men, sport, and spinal cord injury: an analysis of metaphors and narrative types. Disabil Soc 2004; 19, 613-626.

45 Smith B, Sparkes AC. Men, sport, spinal cord injury and the construction of coherence: narrative practice in action. Qual Res 2002; 2, 143-171.

46 Ostrander RN. Meditations on a Bullet: violently injured young men discuss masculinity, disability and blame. Child Adolesc Social Work J 2008; 25, 71-84.

47 Ostrander RN. When identities collide: masculinity, disability and race. Disabil Soc 2008; 23, 585-597.

48 Sakellariou D, Sawada Y. Sexuality after spinal cord injury: the Greek male's perspective. Am J Occup Ther 2006; 60, 311-319.

49 Sakellariou D. If not the disability, then what? barriers to reclaiming sexuality following spinal cord injury. Sex Disabil 2006; 24, 101-111.

50 Gerschick TJ, Miller AS. Coming to terms: masculinity and physical disability. In: Sabo DF and Gordon DFE (eds). Men's Health and IIIness: Gender, Power, and the Body SAGE Publications: Thousand Oaks, California, USA, 1995.

51 Hutchinson SL, Kleiber DA. Heroic masculinity following spinal cord injury: implications for therapeutic recreation practice and research. Ther Recreation J 2000; 34, 42-54.

52 Good GE, Schopp LH, Thomson D, Hathaway S, Sanford-Martens T, Mazurek MO et al. Masculine roles and rehabilitation outcomes among men recovering from serious injuries. Psychol Men Masc 2006; 7, 165-176.

53 Burns SM, Hough S, Boyd BL, Hill J. Men's adjustment to spinal cord injury: the unique contributions of conformity to masculine gender norms. Am J Mens Health 2010; 4, 157-166.

54 Yoshida KK. Reshaping of self: a pendular reconstruction of self and identity among adults with traumatic spinal cord injury. Sociol Health IIIn 2008; 15, 217-245.

55 Carpenter C. The experience of spinal cord injury: the individual's perspectiveimplications for rehabilitation practice. Phys Ther 1994; 74, 614-628.

56 Shuttleworth R. Disabled masculinity: expanding the masculine repertoire. In Smith BG and Hutchison B (eds). Gendering Disability. Rutgers University Press: New Brunswick, NJ, USA, 2004.

57 Seymour W. Remaking the Body: Rehabilitation and Change. Routledge: London, UK, 1998

58 Shakespeare T. The sexual politics of disabled masculinity. Sex Disabil 1999; 17, 53-64.

59 Murphy RF. The Body Silent. A Journey Into Paralysis. Norton: New York, USA, 1990.

60 Good GE, Schopp LH, Thomson D, Hathaway S, Mazurek MO, Sanford-Martens T. Men with serious injuries: relations among masculinity, age, and alcohol use. Rehabil Psychol 2008; 53, 39-45.

61 Shakespeare T. Cultural representation of disabled people: dustbins for disavowal? Disabil Soc 1994; 9, 283-299.

62 Cheng RP. Sociological theories of disability, gender, and sexuality: a review of the literature. J Hum Behav Soc Environ 2009; 19, 112-122.

63 Charmaz K. Stories and silence: disclosures and self in chronic illness. In Brashers E and Goldsmith D (eds). Communicating to Manage Health and IIIness. Taylor and Frances Routledge: New York, 2009.

64 Charmaz K. Identity dilemmas of chronically ill men. Sociol Q 1994; 35, 269-288.

65 Courtenay WH. Constructions of masculinity and their influence on men's well-being: a theory of gender and health. Soc Sc Med 2000; 50, 1385-1401.

66 de Visser R, Smith JA. Mister In-between. J Health Psychol 2006; 11, 685-695.

67 Charles N, Walters V. 'Men are leavers alone and women are worriers': gender differences in discourses of health. Health, $R$ Soc 2008; 10, 117-132.

68 Connell RW. Masculinities. Polity Press: London, UK, 1995.
69 Seidler VJ. Masculinities, bodies, and emotional life. Men and masculinities 2007; 10, 9-21.

70 Robertson S, Sheikh K, Moore A. Embodied masculinities in the context of cardiac rehabilitation. Sociol Health IIIn 2010; 32, 695-710.

71 Esmail S, Darry K, Walter A, Knupp H. Attitudes and perceptions towards disability and sexuality. Disabil Rehabil 2010; 32, 1148-1155.

72 Miers M. Developing an understanding of gender sensitive care: exploring concepts and knowledge. J Adv Nurs 2002; 40, 69-77.

73 Krieger N. Genders, sexes, and health: what are the connections-and why does it matter? Int J Epidemiol 2003; 32, 652-657.

74 Reeve D. Negotiating psycho-emotional dimensions of disability and their influence on identity constructions. Disabil Soc 2002; 17, 493-508.

75 Hughes B. Being disabled: towards a critical ontology for disability studies. Disabil Soc 2007; 22, 673-684.

76 Shackelford M, Farley T, Vines CL. A comparison of women and men with spinal cord injury. Spinal Cord 1998; 36, 337-339.

77 Hyde JS. The gender similarities hypothesis. Am Psychol 2005; 60, 581-592.

78 Rohmer O, Louvet E. Describing persons with disability: salience of disability, gender, and ethnicity. Rehabil Psychol 2009; 54, 76.

79 Watson N. Well, I know this is going to sound very strange to you, but I don't see myself as a disabled person: identity and disability. Disabil Soc 2002; 17, 509-527.

80 Galvin RD. Researching the disabled identity: contextualising the identity transformations which accompany the onset of impairment. Sociol Health IIIn 2005; 27, 393-413.

81 Deal M. Aversive disablism: subtle prejudice toward disabled people. Disabil Soc 2007; 22, 93-107.

82 Shields SA. Gender: an intersectionality perspective. Sex Roles 2008; 59, 301-311. 83 West C, Zimmerman DH. Doing gender. Gend Soc 1987; 1, 125-151.

84 Macintyre S, Hunt K, Sweeting $H$. Gender differences in health: are things really as simple as they seem? Soc Sci Med 1996; 42, 617-624.

85 Annandale E, Hunt K. Masculinity, femininity and sex: an exploration of their relative contribution to explaining gender differences in health. Sociol Health IIIn 1990; 12, 24-46.

86 Cole ER. Intersectionality and research in psychology. Am Psychol 2009; 64, 170.

87 Hankivsky O. Women's health, men's health, and gender and health: implications of intersectionality. Soc Sci Med 2012; 74, 1712-1720.

88 Robertson S. 'I've been like a coiled spring this last week': embodied masculinity and health. Sociol Health IIIn 2006; 28, 433-456.

89 White A. How men respond to illness. Mens Health J 2001; 1, 18-19.

90 Lohan M. How might we understand men's health better? Integrating explanations from critical studies on men and inequalities in health. Soc Sci Med 2007; 65, 493-504.

91 Guilcher SJT, Craven BC, Lemieux-Charles L, Casciaro T, McColl MA, Jaglal SB. Secondary health conditions and spinal cord injury: an uphill battle in the journey of care. Disabil Rehabil 2012: 1-13.

92 Dryden D, Saunders L, Rowe B, May LA, Yiannakoulias N, Svenson LW et al. Utilization of health services following spinal cord injury: a 6-year follow-up study. Spinal Cord 2004; 42, 513-525.

93 Nolan M. The experience of living with spinal cord injury in the early months following discharge from rehabilitation: a qualitative study on a male sample. Doctoral thesis. Department of Health and Human Sciences, Essex University of Essex, 2011.

94 Smith B. Disability, sport and men's narratives of health: a qualitative study. Health Psycho 2013; 32, 110-119. 